\title{
White matter hyperintensities across the adult lifespan: relation to age, $A \beta$ load, and cognition
}

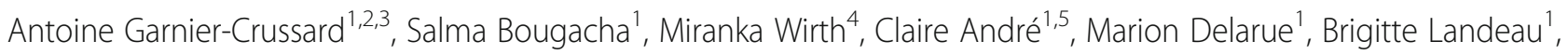
Florence Mézenge ${ }^{1}$, Elizabeth Kuhn ${ }^{1}$, Julie Gonneaud ${ }^{1}$, Anne Chocat ${ }^{1}$, Anne Quillard ${ }^{1}$, Eglantine Ferrand-Devouge ${ }^{1,6,7}$, Vincent de La Sayette ${ }^{5,8}$, Denis Vivien ${ }^{1,9}$, Pierre Krolak-Salmon ${ }^{2,3,10}$ and Gaël Chételat ${ }^{1 *}$ (i)

\begin{abstract}
Background: White matter hyperintensities $(\mathrm{WMH})$ are very frequent in older adults and associated with worse cognitive performance. Little is known about the links between WMH and vascular risk factors, cortical $\beta$-amyloid (A $\beta$ ) load, and cognition in cognitively unimpaired adults across the entire lifespan, especially in young and middle-aged adults.

Methods: One hundred and thirty-seven cognitively unimpaired adults from the community were enrolled (IMAP cohort). Participants underwent (i) a comprehensive neuropsychological assessment of episodic memory, processing speed, working memory, and executive functions; (ii) brain structural T1 and FLAIR MRI scans used for the automatic segmentation of total and regional (frontal, parietal, temporal, occipital, and corpus callosum) WMH; and (iii) a FlorbetapirPET scan to measure cortical $A \beta$. The relationships of total and regional WMH to age, vascular risk factors, cortical $A \beta$, and cognition were assessed within the whole sample, but also splitting the sample in two age groups ( $\leq$ or $>60$ years old).

Results: WMH increased with age across the adult lifespan, i.e., even in young and middle-aged adults. Systolic blood pressure, diastolic blood pressure, and glycated hemoglobin were all associated with higher WMH before, but not after, adjusting for age and the other vascular risk factors. Higher frontal, temporal, and occipital WMH were associated with greater $A \beta$, but this association was no longer significant when adjusting for age and vascular risk factors. Higher total and frontal WMH were associated with worse performance in executive functions, with no interactive effect of the age group. In contrast, there was a significant interaction of the age group on the link between WMH and working memory, which was significant within the subgroup of young/middle-aged adults only. Adding cortical A $\beta$ load in the models did not alter the results, and there was no interaction between WMH and $A \beta$ on cognition.
\end{abstract}

Conclusion: WMH increased with age and were associated with worse executive functions across the adult lifespan and with worse working memory in young/middle-aged adults. A $\beta$ load was weakly associated with WMH and did not change the relationship found between WMH and executive functions. This study argues for the clinical relevance of WMH across the adult lifespan, even in young and middle-aged adults with low WMH.

Keywords: White matter hyperintensities, Cortical Aß, Cognition

\footnotetext{
* Correspondence: chetelat@cyceron.fr

'Normandie Univ, UNICAEN, INSERM, U1237, PhIND "Physiopathology and

Imaging of Neurological Disorders", Institut Blood and Brain @

Caen-Normandie, Cyceron, 14000 Caen, France

Full list of author information is available at the end of the article
}

\section{$\triangle B M C$}

C C The Author(s). 2020 Open Access This article is licensed under a Creative Commons Attribution 4.0 International License, which permits use, sharing, adaptation, distribution and reproduction in any medium or format, as long as you give appropriate credit to the original author(s) and the source, provide a link to the Creative Commons licence, and indicate if changes were made. The images or other third party material in this article are included in the article's Creative Commons licence, unless indicated otherwise in a credit line to the material. If material is not included in the article's Creative Commons licence and your intended use is not permitted by statutory regulation or exceeds the permitted use, you will need to obtain permission directly from the copyright holder. To view a copy of this licence, visit http://creativecommons.org/licenses/by/4.0/ The Creative Commons Public Domain Dedication waiver (http://creativecommons.org/publicdomain/zero/1.0/) applies to the data made available in this article, unless otherwise stated in a credit line to the data. 


\section{Background}

White matter hyperintensities (WMH), visible on T2weighted MRI scans, are frequent in the elderly population, being in patients with cognitive impairment but also in cognitively unimpaired adults older than 60 years old. There is converging evidence for a relationship between increased WMH and decreased cognitive performance, mostly for executive functions, attention, and processing speed, even in older adults with normal cognition [1, 2]. In contrast, only a few studies have investigated the prevalence and regional specificity of WMH in young and middle-aged adults [3-7] or their link with cognition [7-13], and findings are contrasted. Overall, they showed a non-linear increase in WMH with age, with a steeper increase from the fifth or sixth decade $[4,7]$. The midlife period has been previously described as a critical period for cerebrovascular health and regulation of vascular risk factors $[14,15]$ and might thus represent a relevant window for cerebrovascular prevention. Further assessments of WMH in young and middle-aged adults, and of their clinical relevance, thus seem of particular interest to improve our understanding of their impact, and eventually design and monitor prevention interventions.

The presence of cortical $\beta$-amyloid $(\mathrm{A} \beta)$ deposition is another relevant factor to consider in this context as it is one of the main pathological landmark of Alzheimer's disease and it significantly increases with age, including in cognitively unimpaired individuals [16]. Recent findings even showed linear increase in amyloid PET tracer binding from 20 to 60 years old [17]. The association between WMH and cortical $A \beta$ is still debated [18-21] with some studies suggesting that $\mathrm{WMH}$ and cortical $\mathrm{A} \beta$ are independent and additive pathological processes leading to cognitive deficits while others propose that the lesions interact and have synergistic effects on cognition [19, 22-26].

This study aims at providing further insight on total and regional WMH in cognitively unimpaired individuals covering the entire adult lifespan. We will assess the WMH relation to age, vascular risk factors, cortical $A \beta$, and cognition. Then, we will assess the possible interaction between WMH and cortical $A \beta$ on cognition across the adult lifespan.

\section{Methods}

\section{Participants}

One hundred and thirty-seven cognitively unimpaired individuals from the IMAP study (multimodal neuroimaging of early Alzheimer's disease) [27], aged between 19 and 85 (50 participants $<40$ years old, 36 between 40 and 60 years old, and $51>60$ years old), were included in this study. Participants were recruited from the general population through advertisement or word of mouth. They had no history or clinical evidence of major neurological or psychiatric disorder and performed in the normal range in all neuropsychological tests (including tests of episodic memory, working memory, language skills, executive functions, and visuospatial abilities). A regional review board has approved the use of human participants for this study, and consent forms from all participants were obtained. All neuropsychological, MRI, and PET assessments were performed in close temporal proximity (within 3 months). Demographic, clinical, and neuroimaging data are summarized in Table 1 (and Additional file: Table S1 for the two age groups, see below).

\section{Cognitive assessment}

The participants underwent a comprehensive neuropsychological assessment as described in details previously [28]. To obtain robust proxies of cognitive performance and minimize the issue of multiple statistical testing, individual scores were $z$-scored (using the whole sample as the reference) and averaged to compute four individual composite scores reflecting episodic memory, processing speed, working memory, and executive functions. The cognitive scores were available for 136 participants. The episodic memory score included the immediate free recalls and delayed free recall of the Free and Cued Selective Reminding Test [29] (FCSRT; available in all participants $\geq 40$ years old), the memory subscore of the Mattis Dementia Rating Scale [30], and the free recalls of the "encoding, storage, retrieval" paradigm [31]. The processing speed composite score was obtained from the scores (times) at the Trail Making Test (TMT) part A, and color reading and color naming of the Stroop test [32]. The working memory composite score included performance in the forward and backward digit span [33]. The executive functions' composite score was computed from the score at the letter verbal fluency test [32], a score of flexibility calculated on the TMT [32] (time difference between parts $\mathrm{B}$ and A divided by time of part A), and a score of inhibition computed from the Stroop test [32] (time difference between interference and naming tasks). Composite scores were computed in participants in which at least two corresponding individual scores were available. Note that before being averaged, $z$-scores derived from reaction times (i.e., TMT and Stroop) were reversed (multiplied by -1 ) so that higher values always indicated better performance. The correlation matrix between composite scores is presented in Additional file 1 (Figure S1).

\section{Neuroimaging data acquisition and processing Magnetic resonance imaging}

MRI scans were acquired at the Cyceron Center (Caen, France) on a Philips (Eindhoven, The Netherlands) Achieva 3T scanner using a 3D fast-field echo sequence. A highresolution T1-weighted anatomical volume was first acquired using a 3D fast-field echo sequence (3D-T1-FFE sagittal; 180 slices, no gap; slice thickness $=1 \mathrm{~mm}$; field of view $=256 \times 256 \mathrm{~mm}^{2} ; \quad$ in-plane resolution $=1 \times 1 \mathrm{~mm}^{2}$; 
Table 1 Demographic, clinical, and neuroimaging data in the whole population

\begin{tabular}{|c|c|}
\hline N & 137 \\
\hline Age & $49.99 \pm 19.66[19-85]$ \\
\hline Sex (\% male) & $50 \%(N=69)$ \\
\hline Level of education (years) & $13.11 \pm 3.30[7-20]$ \\
\hline $\mathrm{SBP}^{1}(\mathrm{mmHg})$ & $133.92 \pm 19.27[95-198]$ \\
\hline $\mathrm{DBP}^{1}(\mathrm{mmHg})$ & $78.32 \pm 11.03[54-118]$ \\
\hline $\mathrm{HbA} 1 \mathrm{C}^{2}(\%)$ & $5.46 \pm 0.40[4.50-6.80]$ \\
\hline Episodic memory ${ }^{3}$ & $0.03 \pm 0.68[-2.11-1.89]$ \\
\hline Processing speed ${ }^{3}$ & $0.00 \pm 0.84[-2.77-1.77]$ \\
\hline Working memory ${ }^{3}$ & $0.00 \pm 0.86[-1.60-2.58]$ \\
\hline Executive functions $^{3}$ & $0.00 \pm 0.66[-2.66-1.41]$ \\
\hline Total WMH $\left(\mathrm{cm}^{3}\right)$ & $2.74 \pm 5.07[0-34.90]$ \\
\hline Frontal WMH $\left(\mathrm{cm}^{3}\right)$ & $0.91 \pm 2.02[0-14.92]$ \\
\hline Parietal WMH $\left(\mathrm{cm}^{3}\right)$ & $0.68 \pm 1.57[0-9.57]$ \\
\hline Temporal WMH $\left(\mathrm{cm}^{3}\right)$ & $0.33 \pm 0.60[0-3.11]$ \\
\hline Occipital WMH $\left(\mathrm{cm}^{3}\right)$ & $0.34 \pm 0.63[0-4.65]$ \\
\hline Callosal WMH $\left(\mathrm{cm}^{3}\right)$ & $0.33 \pm 0.65[0-4.09]$ \\
\hline$A \beta$ load $^{4}$ (SUVR) & $1.17 \pm 0.10[0.97-1.64]$ \\
\hline$A \beta$ positive participants ${ }^{4}(\%$; Number) & $6 \%(N=6)$ \\
\hline $\operatorname{TIV}\left(\mathrm{dm}^{3}\right)$ & $1.37 \pm 0.13[1.09-1.62]$ \\
\hline
\end{tabular}

Numbers are expressed as mean \pm standard deviation; the ranges are shown in brackets, or percentage (for the sex)

$S B P$ systolic blood pressure, $D B P$ diastolic blood pressure, $H b A 1 C$ glycated hemoglobin, $W M H$ white matter hyperintensities, TIV total intracranial volume

${ }^{1}$ Data available for 133 participants

${ }^{2}$ Data available for 128 participants

${ }^{3}$ Data available for 136 participants

${ }^{4}$ Data available for 109 participants

repetition time $\mathrm{TR}=20 \mathrm{~ms}$; echo time $\mathrm{TE}=4.6 \mathrm{~ms}$; flip angle $=10$ ). Then, a high-resolution T2-weighted FLAIR anatomical volume was collected (3D-IR sagittal; TR/TE/ $\mathrm{TI}=8000 / 348 / 2400 \mathrm{~ms}$; flip angle $=90^{\circ} ; 90$ slices, no gap; slice thickness $=2 \mathrm{~mm}$; field of view $=250 \times 250 \mathrm{~mm}^{2}$; inplane resolution $=0.78 \times 0.78 \mathrm{~mm}^{2}$ ). The T1-weighted images were segmented, spatially normalized to the Montreal Neurological Institute (MNI) space using the segmentation routine implemented in Statistical Parametric Mapping 12 (SPM12). Total intracranial volume (TIV) was estimated using SPM12.

\section{Assessment of WMH}

Raw FLAIR images were coregistered to their corresponding native space T1-weighted scan, and white matter lesions were segmented using the lesion prediction algorithm (LPA (Schmidt [34], Chapter 6.1)) as implemented in the Lesion Segmentation Toolbox version 2.0.15 (www.statistical-modelling.de/lst.html) for SPM (SPM12, MatLab v.2018b; MathWorks, Natick, MA), based on the calculation of a lesion probability score for each voxel. A minimum extend threshold was set to
$0.01 \mathrm{~cm}^{3}$. Lesion probability maps were binarized by applying a threshold of 0.5 [35], and lesion masks were thereby generated. Lesion masks were visually inspected and corrected for false positives in corticospinal tracts if necessary using a specific corticospinal tract mask for each participant (corticospinal hyperintensities are common artifacts in WMH segmentations [36]). Next, Hammers and JHU white matter adult atlases [37-39] were normalized back to the native space of each individual binary lesion map to extract the mean regional WMH volumes in the frontal, temporal, parietal, and occipital lobes and in the corpus callosum. WMH volume in cubic centimeter was defined as the voxel size multiplied by the total number of voxels labeled as lesions in the cerebrum.

\section{Florbetapir ( $F^{18}$-AV45) PET}

Florbetapir-PET data were available for 109 participants. Florbetapir-PET scans were acquired on a Discovery RX VCT 64 PET-CT device (General Electric Healthcare) at the Cyceron Center (Caen, France) to measure cortical A $\beta$ load. Participants underwent an intravenous injection of $\sim 4 \mathrm{MBq} / \mathrm{kg}$ of Florbetapir, and scans were acquired with a resolution of $3.76 \times 3.76 \times 4.9 \mathrm{~mm}^{3}$ (field of view $=157$ $\mathrm{mm})$. Forty-seven planes were obtained with a voxel size of $1.95 \times 1.95 \times 3.27 \mathrm{~mm}^{3}$. A transmission scan was performed for attenuation correction before acquisition. PET images were coregistered onto the corresponding MRI and spatially normalized using the deformation parameters derived from the MRI procedure. The resulting images underwent quantitative scaling, using cerebellar gray matter as a reference to obtain standardized uptake value ratio (SUVR) images. Finally, Florbetapir SUVR images were masked to exclude non-gray matter voxels. Normalized and scaled Florbetapir-PET images were used to extract an averaged index of cortical $A \beta$, using a predetermined neocortical mask (including the entire gray matter, except the cerebellum, occipital and sensory motor cortices, hippocampi, amygdala, and basal nuclei) [40]. Florbetapir-PET SUVR data were mainly used as a continuous variable in the analyses; for some analyses, however, they were also dichotomized as amyloid positive versus negative using a cutoff corresponding to the 99.9th percentile of SUVR distribution among cognitively unimpaired young adults aged $<40$ years $(n=45)$ [41].

\section{Assessment of covariates}

Sociodemographic variables consisted of age, sex, and level of education. Vascular risk factors were systolic blood pressure (SBP), diastolic blood pressure (DBP), and glycated hemoglobin (HbA1C, 9 missing data). SBP and DBP (4 missing data) were averaged over 6 assessments (three consecutive measures at two different times). The 
correlation matrix between age and the different vascular risk factors is presented in Additional file 1 (Figure S1).

\section{Statistical analyses}

Statistical analyses were performed using the R software version 3.5.2, 2018 ( $\mathrm{R}$ Core Team, www.R-project.org). In models where WMH were included as dependent variables, due to the non-normal distribution of $\mathrm{WMH}$, raw WMH values (+ 0.01 to avoid zeros) were logtransformed as usually performed [5, 13, 42].

To assess the relationship between log-transformed WMH (total and regional volumes), age, vascular risk factors, and cortical $\mathrm{A} \beta$, regression analyses were performed using log-transformed WMH volume as the dependent variable, and age, sex, SBP, DBP, HbA1C, A $\beta$, and TIV as predictors. Model 1 was only adjusted for TIV, and model 2 was additionally adjusted for all significant covariates in model 1 (among age, sex, SBP, $\mathrm{DBP}, \mathrm{HbA} 1 \mathrm{C}$, and $\mathrm{A} \beta$ ). Age was treated as a continuous variable in all these analyses.

Then, we wanted to assess whether the age effect on total WMH (log-transformed and raw volumes) was present even in young and middle-aged adults. For this purpose, participants were split in two age groups: young and middle-aged adults $\leq 60$ years old $(N=86$, mean age $37.41 \pm 12.85)$ and older adults $>60$ years old $(N=51$, mean age $71.20 \pm 6.26$ ) (details in Additional file: Table S1). First, we added the age group (as a binary variable) as an interactive term in models 1 and 2 and tested for the possible interaction of this factor. Second, we rerun all analyses (models 1 and 2) within each age group separately. Finally, for the sake of completeness, we rerun all analyses in a subgroup of young adults $\leq 40$ years old $(N=50$, mean age $27.86 \pm 6.13)$.

Then, to assess the relationship between WMH (total and regional volumes) and cognition, multiple regression analyses were performed using each composite cognitive score as the dependent variable and raw WMH as a predictor, controlling for age, sex, level of education, and TIV (model A). We also tested for the interactive effect of the age group (as a binary variable) and, when significant, repeated the same analyses within each age group separately. The model was next rerun for each cognitive score including $A \beta$ as a second predictor (model $B$ ) to evaluate if the WMH effects on cognition persisted when controlling for the possible effect of A $\beta$. Finally, a WMH by $A \beta$ interaction term was added (model $C$ ) to assess whether these two variables had an interactive effect on cognition. In case of missing data, the participant was excluded from the corresponding analysis.

The significance level was set to $p<0.05$. For analyses across the whole sample, Bonferroni-corrected $p$ values accounting for multiple testing across the 4 cognitive domains (episodic memory, processing speed, working memory, and executive functions) were calculated.

\section{Results}

Relationships of WMH to age, vascular risk factors, and $A \beta$ Increased total and regional log-transformed WMH were associated with increased age in the whole population, both in models 1 and 2 (Fig. 1a, c; Table 2). In addition, SBP, DBP, and HbA1C were positively associated with global and regional WMH in model 1 (only adjusted for TIV), i.e., higher WMH were associated with higher SBP, DBP, or HbA1C. These associations were no longer significant in model 2 except for SBP and parietal WMH (Table 2).

Frontal, temporal, and occipital WMH were positively associated with $A \beta$ in model 1, i.e., higher $\mathrm{WMH}$ in these regions were associated with higher $A \beta$ load, but this association was not found in model 2 (Table 2). This result was identical when using $A \beta$ as a binary, instead of a continuous variable.

There was no significant interaction of the age group on the relationship between age and total WMH $(p=0.10)$, indicating that the effect of age on log-transformed WMH is present and similar within the older adults and the young/middle-aged participants (Additional File: Figure S2). Increased total log-transformed WMH with age was even found in the subgroup of adults younger than 40 years old (see Additional file 1: Table S2 and Figure S3). As expected, when considering raw WMH (instead of logtransformed WMH), a significant interaction of the age group was found $(p<0.001)$, with a steeper decline in older adults than in young/middle-aged participants (Fig. 1b). Moreover, there was no interaction of the age group on the relationship between SBP, DBP, HbA1C, and total WMH, neither in model 1 nor in model 2 . In contrast, we found in model 1 an interactive effect of the age group on the link between $A \beta$ and WMH $(p=0.01)$, but this effect was no longer significant in model 2. Results within each age group are detailed in Table 3.

\section{Associations between WMH and cognition}

We first assessed the relationships between WMH and cognitive scores, adjusted for age, sex, level of education, and TIV (model A). Worse performance in executive functions was associated with total WMH and frontal WMH (Table 4, Fig. 2). Associations were also found between executive functions and parietal WMH $(\beta=-0.20$, uncorrected $p=$ $0.02)$, occipital WMH $(\beta=-0.22$, uncorrected $p=0.01)$, and callosal WMH $(\beta=-0.20$, uncorrected $p=0.02)$, but the associations did not survive Bonferroni correction for multiple comparisons (Bonferroni-corrected $p=0.09,0.05$, and 0.08 , respectively). There was no interactive effect of the age group on the relationships between $\mathrm{WMH}$ and 
A.
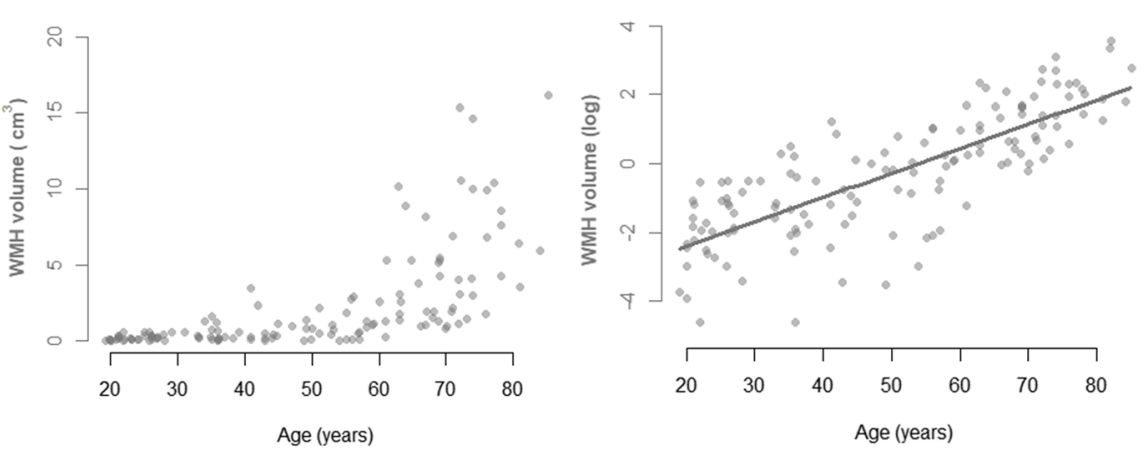

B.
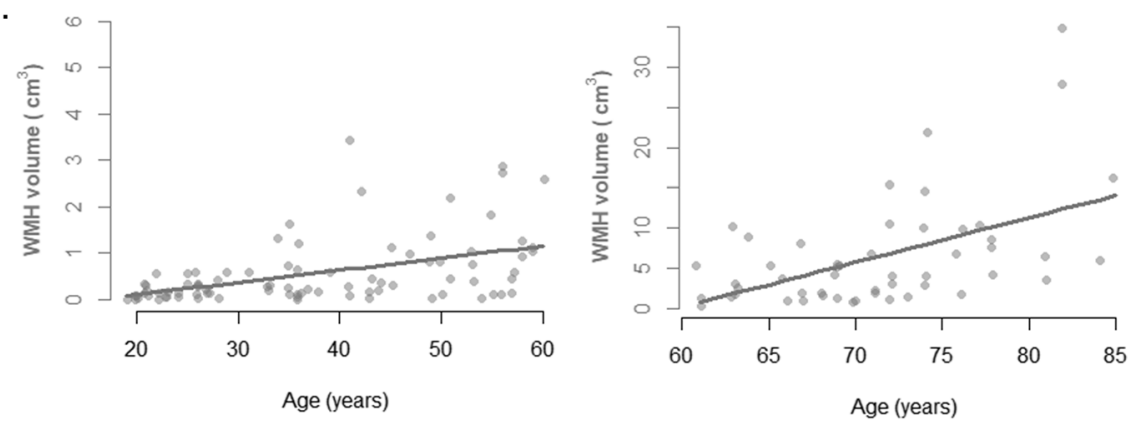

C.

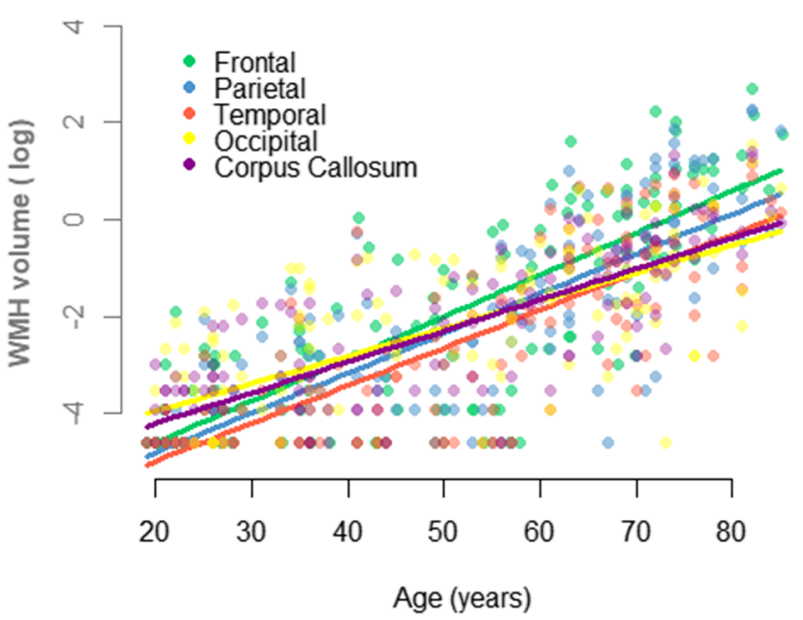

Fig. 1 Relationship between WMH and age across the adult lifespan. a Total WMH as a function of age across the adult lifespan (raw volumes on the left; log-transformed volumes and linear regression curve on the right). $\mathbf{b}$ Total raw WMH as a function of age in young/middle-aged adults (on the left) and in older adults (on the right), with regression linear curve; the scale of the $y$ axis is different for the two groups. c Regional logtransformed WMH (frontal, parietal, temporal, occipital, and corpus callosum) as a function of age across the adult lifespan

executive functions ( $p>0.30$ in all regions), suggesting that the association between WMH and executive functions was present across the entire adult lifespan, and not only in a specific age group. Composite scores of episodic memory, processing speed, and working memory were not significantly associated with WMH (Fig. 2, Additional file 1: Table S3), but there was a significant interaction between WMH and age group on working memory, suggesting a different effect of WMH on working memory in each group ( $p=$ 0.02 ). In the subgroup of young/middle-aged adults, total
WMH were significantly associated with working memory $(\beta=-0.28, p=0.02)$. No association was found in the subgroup of older adults ( $\beta=-0.14, p=0.36$ ) (Fig. 3).

The association between total or regional WMH and executive functions found in the entire sample was still significant when adding $A \beta$ load in the model, suggesting that WMH effect is independent from $A \beta$ load. $A \beta$ load was not associated with executive functions in that model (Table 4 , model $B$ ). This result remained unchanged when $A \beta$ was considered as a binary variable. Finally, there was no 
Table 2 Relationships between WMH, age, vascular risk factors, and A $\beta$

\begin{tabular}{|c|c|c|c|c|c|c|c|c|c|c|c|c|c|c|c|}
\hline & \multicolumn{5}{|c|}{ Total WMH } & \multicolumn{5}{|c|}{ Frontal WMH } & \multicolumn{5}{|c|}{ Parietal WMH } \\
\hline & \multicolumn{2}{|c|}{ Model 1} & \multicolumn{2}{|c|}{ Model 2} & & \multicolumn{2}{|c|}{ Model 1} & \multicolumn{2}{|c|}{ Model 2} & & \multicolumn{2}{|c|}{ Model 1} & \multicolumn{2}{|c|}{ Model 2} & \\
\hline & $\beta$ & $p$ & $\beta$ & $p$ & $R^{2}$ & $\beta$ & $p$ & $\beta$ & $p$ & $R^{2}$ & $\beta$ & $p$ & $\beta$ & $p$ & $R^{2}$ \\
\hline Age & 0.80 & $<0.001$ & 0.73 & $<0.001$ & 0.66 & 0.81 & $<0.001$ & 0.79 & $<0.001$ & 0.69 & 0.80 & $<0.001$ & 0.77 & $<0.001$ & 0.65 \\
\hline Sex & 0.00 & 0.99 & - & - & & -0.01 & 0.90 & - & - & & 0.10 & 0.41 & - & - & \\
\hline SBP & 0.51 & $<0.001$ & 0.13 & 0.10 & & 0.51 & $<0.001$ & 0.12 & 0.17 & & 0.55 & $<0.001$ & 0.22 & $<0.01$ & \\
\hline DBP & 0.41 & $<0.001$ & -0.02 & 0.78 & & 0.41 & $<0.001$ & -0.05 & 0.56 & & 0.40 & $<0.001$ & -0.11 & 0.13 & \\
\hline $\mathrm{HbA} 1 \mathrm{C}$ & 0.52 & $<0.001$ & 0.00 & 0.95 & & 0.53 & $<0.001$ & 0.02 & 0.81 & & 0.51 & $<0.001$ & -0.03 & 0.61 & \\
\hline \multirow[t]{4}{*}{$A \beta$} & 0.19 & 0.05 & - & - & & 0.19 & 0.04 & -0.02 & 0.68 & & 0.09 & 0.34 & - & - & \\
\hline & \multicolumn{5}{|c|}{ Temporal WMH } & \multicolumn{5}{|c|}{ Occipital WMH } & \multicolumn{4}{|c|}{ Callosal WMH } & \\
\hline & \multicolumn{2}{|c|}{ Model 1} & \multicolumn{2}{|c|}{ Model 2} & & \multicolumn{2}{|c|}{ Model 1} & \multicolumn{2}{|c|}{ Model 2} & & \multicolumn{2}{|c|}{ Model 1} & \multicolumn{2}{|c|}{ Model 2} & \\
\hline & $\beta$ & $p$ & $\beta$ & $p$ & $R^{2}$ & $\beta$ & $p$ & $\beta$ & $p$ & $R^{2}$ & $\beta$ & $p$ & $\beta$ & $p$ & $R^{2}$ \\
\hline Age & 0.83 & $<0.001$ & 0.79 & $<0.001$ & 0.71 & 0.69 & $<0.001$ & 0.58 & $<0.001$ & 0.51 & 0.77 & $<0.001$ & 0.74 & $<0.001$ & 0.6 \\
\hline Sex & 0.04 & 0.73 & - & - & & 0.12 & 0.32 & - & - & & -0.07 & 0.58 & - & - & \\
\hline SBP & 0.48 & $<0.001$ & 0.07 & 0.38 & & 0.47 & $<0.001$ & 0.20 & 0.07 & & 0.51 & $<0.001$ & 0.14 & 0.11 & \\
\hline DBP & 0.37 & $<0.001$ & -0.06 & 0.43 & & 0.30 & $<0.001$ & -0.10 & 0.31 & & 0.40 & $<0.001$ & -0.03 & 0.75 & \\
\hline $\mathrm{HbA} 1 \mathrm{C}$ & 0.55 & $<0.001$ & 0.07 & 0.33 & & 0.48 & $<0.001$ & 0.07 & 0.43 & & 0.48 & $<0.001$ & -0.04 & 0.58 & \\
\hline$A \beta$ & 0.23 & 0.02 & 0.00 & 0.97 & & 0.20 & 0.04 & 0.05 & 0.48 & & 0.15 & 0.11 & - & - & \\
\hline
\end{tabular}

Standardized betas $(\beta)$ and $p$ values are reported from regression models where total and regional WMH (log-transformed) are regressed onto age, sex, SBP, DBP, $\mathrm{HbA} 1 \mathrm{C}$, and $\mathrm{A} \beta$ controlling for TIV (model 1) or TIV and significant covariates (model 2). Adjusted $R^{2}$ values were indicated for model 2 . Significant $p$ values $(<$ $0.05)$ are in bold

Analyses were performed with 137 participants for age and sex, 133 participants for SBP and DBP, 128 participants for HbA1C, and 109 participants for A $\beta$ in model 1. Analyses were performed with 125 participants (for total, parietal, and callosal WMH) and 99 participants when $A \beta$ was included (for frontal, temporal, and occipital WMH) in model 2. SBP systolic blood pressure, DBP diastolic blood pressure, HbA1C glycated hemoglobin, $A \beta$ cortical $\beta$-amyloid, TIV total intracranial volume

significant interaction between $A \beta$ load and total or regional WMH on executive functions (Table 4, model C).

\section{Discussion}

Our aim was to highlight the links between total and regional $\mathrm{WMH}$, age, vascular risk factors, $\mathrm{A} \beta$, and cognitive performance across the adult lifespan. We found that (i) WMH increased with age, in a steeper way in older age but already significantly in young and middle-aged adults; WMH also showed an age-dependent relationship with vascular risk factors; (ii) frontal, temporal, and occipital WMH were associated with higher $A \beta$, but this

Table 3 Relationships between total WMH, age, vascular risk factors, and A $\mathrm{B}$ in the subgroup of young/middle-aged adults (A) and in the subgroup of older adults (B)

\begin{tabular}{|c|c|c|c|c|c|c|c|c|c|c|c|}
\hline \multirow[t]{3}{*}{ (A) } & \multicolumn{5}{|c|}{ Total WMH } & \multirow[t]{3}{*}{ (B) } & \multicolumn{5}{|c|}{ Total WMH } \\
\hline & \multicolumn{2}{|c|}{ Model 1} & \multicolumn{3}{|c|}{ Model 2} & & \multicolumn{2}{|c|}{ Model 1} & \multicolumn{3}{|c|}{ Model 2} \\
\hline & $\bar{\beta}$ & $p$ & $\bar{\beta}$ & $p$ & $R^{2}$ & & $\beta$ & $p$ & $\beta$ & $p$ & $R^{2}$ \\
\hline Age & 0.47 & $<0.001$ & 0.35 & 0.01 & 0.32 & Age & 0.53 & $<0.001$ & 0.42 & 0.01 & 0.26 \\
\hline Sex & -0.05 & 0.72 & - & - & & Sex & -0.03 & 0.89 & - & - & \\
\hline SBP & 0.24 & 0.02 & 0.01 & 0.96 & & SBP & 0.35 & 0.02 & 0.10 & 0.51 & \\
\hline DBP & 0.37 & $<0.001$ & 0.23 & 0.10 & & $\mathrm{DBP}$ & 0.19 & 0.19 & - & - & \\
\hline $\mathrm{HbA} 1 \mathrm{C}$ & 0.20 & 0.06 & - & - & & $\mathrm{HbA} 1 \mathrm{C}$ & 0.39 & 0.01 & 0.20 & 0.17 & \\
\hline$A \beta$ & 0.24 & 0.05 & 0.09 & 0.39 & & $A \beta$ & -0.23 & 0.14 & - & - & \\
\hline
\end{tabular}

Standardized betas $(\beta)$ and $p$ values are reported from regression models where total WMH (log-transformed) are regressed onto age, sex, SBP, DBP, HbA1C, and $A \beta$ controlling for TIV (model 1), or for TIV and significant covariates (model 2 ) in young/middle-aged adults $(A ; N=86$, mean age $37.41 \pm 12.85)$ and in older adults $(\mathrm{B}, N=51$, mean age $71.20 \pm 6.26)$. Adjusted $R^{2}$ were indicated for model 2 . Significant $p$ values $(<0.05)$ are in bold

For young/middle-aged adults, analyses were performed with 86 participants for age and sex, 85 participants for SBP and DBP, 80 participants for HbA1C, and 65 participants for $A \beta$ in model 1 and with 65 participants in model 2. For older adults, analyses were performed with 51 participants for age and sex; 48 participants for $\mathrm{SBP}, \mathrm{DBP}$, and $\mathrm{HbA1C}$; and 44 participants for $\mathrm{A} \beta$ in model 1 and with 45 participants in model 2

SBP systolic blood pressure, DBP diastolic blood pressure, HbA1C glycated hemoglobin, $A \beta$ cortical $\beta$-amyloid, TIV total intracranial volume 
Table 4 Association between $W M H, A \beta$, and executive functions

\begin{tabular}{|c|c|c|c|c|c|c|c|c|c|c|c|c|c|c|c|c|c|c|c|}
\hline & & \multicolumn{3}{|l|}{ Total } & \multicolumn{3}{|l|}{ Frontal } & \multicolumn{3}{|c|}{ Parietal } & \multicolumn{3}{|c|}{ Temporal } & \multicolumn{3}{|c|}{ Occipital } & \multicolumn{3}{|c|}{ Corpus callosum } \\
\hline & & $\bar{\beta}$ & $p$ & $R^{2}$ & $\beta$ & $p$ & $R^{2}$ & $\beta$ & $p$ & $R^{2}$ & $\bar{\beta}$ & p & $R^{2}$ & $\beta$ & p & $R^{2}$ & $\bar{\beta}$ & $p$ & $R^{2}$ \\
\hline Model A & WMH & -0.23 & 0.048 & 0.30 & -0.25 & 0.02 & 0.31 & -0.20 & 0.09 & 0.29 & -0.06 & 1.00 & 0.27 & -0.22 & 0.05 & 0.30 & -0.20 & 0.08 & 0.29 \\
\hline \multirow[t]{2}{*}{ Model B } & WMH & -0.32 & 0.01 & 0.30 & -0.33 & 0.00 & 0.31 & -0.28 & 0.02 & 0.29 & -0.15 & 0.62 & 0.25 & -0.32 & 0.01 & 0.31 & -0.26 & 0.04 & 0.28 \\
\hline & $A \beta$ & 0.06 & 1.00 & & 0.05 & 1.00 & & 0.07 & 1.00 & & 0.10 & 1.00 & & 0.09 & 1.00 & & 0.06 & 1.00 & \\
\hline Model C & $\mathrm{WMH} \times \mathrm{A} \beta$ & -0.07 & 1.00 & 0.30 & 0.61 & 1.00 & 0.31 & -0.15 & 1.00 & 0.29 & -0.14 & 1.00 & 0.24 & -0.70 & 1.00 & 0.31 & 0.45 & 1.00 & 0.28 \\
\hline
\end{tabular}

Standardized betas $(\beta)$, corrected $p$ values, and adjusted $R^{2}$ values are reported from regression models where composite scores of executive functions are regressed onto $\mathrm{WMH}$ (model A), WMH and $\mathrm{A} \beta$ (model B), and the interaction between WMH and A $\beta$ (model C). All models are controlled for age, sex, level of education, and TIV. Significant $p$ values $(<0.05)$ after applying Bonferroni correction (accounting for multiple testing across the 4 cognitive domains) are in bold. Analyses were performed with 136 participants in model A and with 109 participants in models $B$ and $C$

$W M H$ white matter hyperintensities, $A \beta$ cortical $\beta$-amyloid

association was no longer significant when controlling for age and vascular risk factors; and (iii) higher total and frontal WMH were associated with lower performance in executive functions across the population including young and middle-aged adults, but not with lower performance in episodic memory and processing speed. Working memory was associated with WMH only in the subgroup of young/middle-aged adults. This effect of WMH was not driven by $A \beta$ load, and there was no interaction between WMH and $A \beta$ load on cognition.

The increase in WMH with age is classically described in older adults [43]. Given the presumed vascular origin

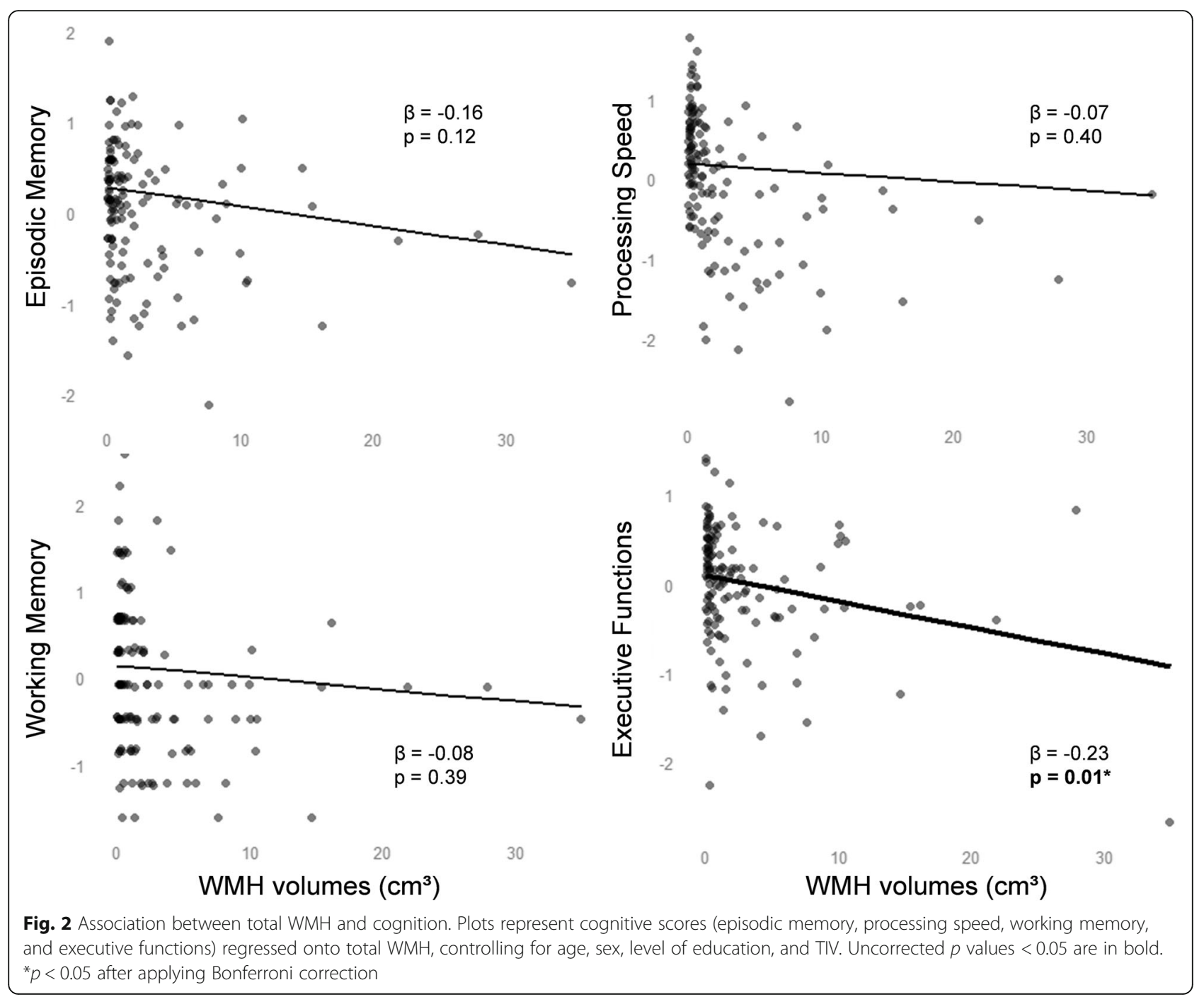




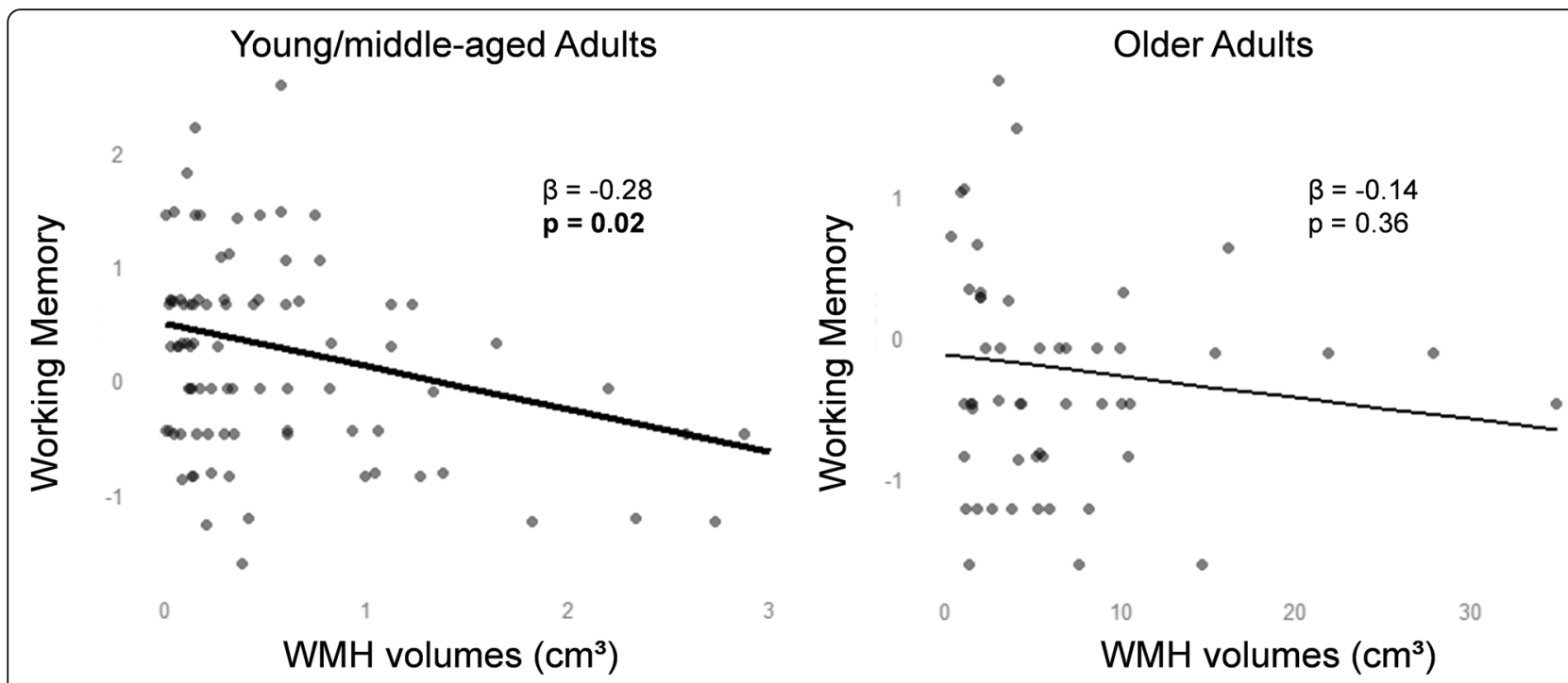

Fig. 3 Association between total WMH and working memory in the subgroup of young/middle-aged adults and in the subgroup of older adults. Plots represent composite scores of working memory regressed onto total WMH, controlling for age, sex, level of education, and TIV, in young/ middle-aged adults ( $N=86$, mean age $37.41 \pm 12.85$ ) on the left and in older adults $(N=51$, mean age $71.20 \pm 6.26)$ on the right. $p$ values $<0.05$ are in bold

of $\mathrm{WMH}$, it is thought to reflect, at least partly, small vessel disease, which is an age-related disease [44]. While studies in older adults are numerous and constantly report increased WMH with age, fewer studies have assessed this question in younger participants, i.e., before 60 years old [3-7]. These studies found an agerelated increase in WMH already in middle-aged adults, probably from the fifth or sixth decade $[3,4,7]$. An inflection point of 43 years old, where total WMH would start increasing with age, was recently reported [7]. However, this increase likely starts even earlier as WMH were found to be common already in the brains of healthy individuals aged 44-48 years, with an estimated prevalence of 50.9\% [5]. Our findings support this hypothesis as they show an age-related increase in WMH even in young and middle-aged adults (and even in a subgroup of participants under 40 years old). Altogether, these findings show that WMH are not only accumulating in old ages but are also slightly increasing with age already in middle-aged and even in young adults.

These younger life periods are considered as critical for cerebrovascular health and might thus represent a strategic time window for preventive trials $[12,14,15]$. Previous studies classically report a link between WMH and vascular risk factors, and a recent report, including more than 8000 participants, confirmed the link between WMH and hypertension, tobacco smoking, and diabetes [4, 42, 45]. In the present study, increased WMH were associated with higher SBP, DBP, or HbA1C. This association was no longer significant when age and other covariates (model 2) were taken into account (except for SBP and parietal WMH), suggesting that age was the main driver of the link between WMH and vascular risk factors. This finding likely reflects the facts that participants were particularly healthy, our population was not enriched for vascular risk factors, and individuals with instable chronic disease or symptomatic cerebrovascular diseases were not included.

Higher frontal, temporal, and occipital WMH correlated to higher $A \beta$ load. This association was not found with total WMH and with other regional WMH and was no longer significant in model 2, i.e., the multi-adjusted model including age and vascular risk factors as covariates. In the literature, results are also contrasted; while the majority of studies found no association between WMH and $A \beta$ load [19], a recent study showed such an association in 424 participants aged 50 to 89 years old without dementia [20]. It is possible that this association is very subtle and only measurable in very large sample and/or in this specific age range.

We also found specific relationships between WMH and cognition and more specifically between increased total and frontal WMH and worse performance in executive functions. This relationship between WMH and cognition is consistent with many studies, altogether showing a small but robust effect of WMH on cognitive performance and especially on executive functions $[2,7,46]$. The specific relationship with executive functions, thought to be mainly supported by frontal areas, might reflect the fact that global and regional WMH disrupt long-distance white matter tracts notably involving connections with the frontal cortex [47, 48]. In line with this hypothesis, regional WMH, even 
non-frontal WMH, have been associated with lower glucose metabolism in frontal areas and executive functions in cognitively unimpaired older adults [49].

Most studies assessing the links between WMH and cognition focused on elderly populations. This question is rarely assessed in young and/or middle-aged adults, and results are contrasted [7-13]. While one previous study did not find any significant relationship between WMH and cognition in a group of cognitively unimpaired individuals including both young and middle-aged adults (i.e., from 20 to 60 years old) [8], more recent studies showed a negative association between total WMH and cognition in samples including both middle-aged and older participants (i.e., aged from 40 to 75 years old) [9-13]. We did not find the age group to affect the relationships between WMH and executive functions, suggesting that this effect is not limited to a specific age group but existed across the entire adult lifespan. There was an interaction between WMH and age group on working memory, suggesting a different effect of WMH on working memory between groups. Indeed, an association was found only in the subgroup of young/middle-aged adults, highlighting an early effect of WMH on working memory. The absence of significant association in the subgroup of older adults could be due to a lack of power related to the more limited size of the subgroup.

Pending replications, our findings thus suggest that WMH in adults, including young and middle-aged adults with very low total WMH (mean volume in the whole sample $=2.7$ $\mathrm{cm}^{3}$ ), are associated with worse cognitive performance and should not be considered as fully silent (asymptomatic) lesions. These results highlight the importance to detect WMH in adults to propose interventions for secondary prevention at this early adulthood stage. We did not find significant associations between WMH and composite scores of episodic memory and processing speed, even if those associations have already been described [2, 7]. This might reflect the facts that these associations are more subtle and could only be detected in larger sample especially as our sample was very healthy and show limited variability, i.e., both low WMH severity and high cognitive performance.

Finally, we found that WMH effects on executive functions persisted when adding $A \beta$ load in the models. This suggests that cortical $A \beta$, which is one of the main pathological landmark of Alzheimer's disease, did not participate to the negative effect of WMH on executive functions in our sample. No interaction was found between $W M H$ and $A \beta$ suggesting that $W M H$ and $A \beta$ act rather independently as additive but not interactive processes. The additive or interactive relationship between cerebrovascular lesions, such as WMH, and Alzheimer's pathology, including $A \beta$, is still debated. There are arguments supporting additive and independent effects of those lesions [50-52] while other studies argue that WMH and $A \beta$ have synergistic associations with cognition [25, 26, 53]. The present study is not designed to address this specific question.

\section{Limitations}

The main limitation is the observational and crosssectional design of the study, preventing us from disentangling state effects from dynamic effects and from making causal interpretations. Another limitation is the use of automatic segmentation of WMH, which might be associated with increased risk of false positives or negatives compared to manual delineation. Also, we were specifically interested on WMH in the present study; for an overall comprehensive assessment of the effects of vascular lesions on cognition, other vascular lesions-such as cerebral lacunes or cortical microbleeds-should be considered. Finally, the measurement of Tau pathology, in vivo using PET with Tau radiotracers or with cerebrospinal fluid biomarkers, would allow assessing the interactions between both Alzheimer's pathological landmarks and cerebrovascular pathology, even if recent studies failed to find an association between Tau pathology and WMH [20,54].

The strengths and originality of this study rely on the presence of quantitative and homogeneous measurements of total and regional WMH on the one hand, and of $A \beta$ on the other hand, combined with a detailed cognitive evaluation, in a sample of cognitively unimpaired individuals covering the entire adult lifespan, including young and middle-aged adults.

\section{Conclusion}

This cross-sectional study found a significant effect of age on WMH across the adult lifespan, including in young and middle-aged adults. We highlighted associations between higher WMH and lower performance in executive functions, independently from $A \beta$, across the entire adult lifespan. These results suggest that WMH, even in young and middle-aged adults with low volumes, are clinically meaningful and should not be considered as fully silent lesions.

\section{Supplementary information}

Supplementary information accompanies this paper at https://doi.org/10. 1186/s13195-020-00669-4.

Additional file 1: Table S1 Demographic, clinical and neuroimaging data in the subgroup of young/middle-aged adults and in the subgroup of older adults. Figure S1. Correlation matrices. Figure S2 Relationships between regional WMH and age in the subgroup of young/middle-aged adults and in the subgroup of older adults, and interactive effects between age groups. Table S2 Relationships between WMH, vascular risk factors and $A \beta$ in the subgroup of young adults $\leq 40$ years. Figure S3 Total WMH as a function of age in adults younger than 40 years old. Table S3 Associations between WMH and cognition in the whole sample. 


\section{Abbreviations}

A $\beta$ : Cortical $\beta$-amyloid; DBP: Diastolic blood pressure; FDR: False discovery rate; HbA1C: Glycated hemoglobin; FLAIR: Fluid-attenuated inversion recovery; SUVR: Standardized uptake value ratio; SBP: Systolic blood pressure; TIV: Total intracranial volume; WMH: White matter hyperintensities

\section{Acknowledgements}

The authors are grateful to G. Rauchs, E. Arenaza-Urquijo, A. Bejanin, C. Tomadesso, S. Egret, M. Fouquet, R. La Joie, R. De Flores, M. Leblond, C. Malle, K. Mevel, J. Mutlu, V. Ourry, A. Pelerin, A. Perrotin, G. Poisnel, S. Segobin, N. Villain, A. Manrique, L. Paly, E. Touron, I. Moulinet, S. Rehel, S. Dautricourt, V. Lefranc, A. Cognet, F. Viader, M. Gaubert, A. Abbas, L. Barré, D. Guilloteau, F. Pasquier, S. Belliard, A. Lutz, F. Eustache, B. Desgranges and the Cyceron MRIPET staff members, and to the participants of the study.

\section{Authors' contributions}

AGC, SB, PKS, and GC contributed to the study concept and design. CA, MD, $\mathrm{BL}, \mathrm{FM}, \mathrm{EK}, \mathrm{JG}, \mathrm{DV}$, and $\mathrm{GC}$ took part in the acquisition and processing of the data, and quality check control. Analysis and interpretation of MRI data were done by $A G C, S B, B L, P K S$, and GC. AC, AQ, EFG, and VDLS took part in participants' recruitment and selection process, clinical evaluation, and monitoring of participants. AGC and SB contributed to the statistical analysis. AGC and GC drafted the manuscript. PKS and GC took part in the study supervision. All authors took part in revising the manuscript for content. The authors read and approved the final manuscript.

\section{Funding}

This work was supported by the Institut National de la Santé et de la Recherche Medicale (INSERM), the Programme Hospitalier de Recherche Clinique (PHRCN 2011-A01493-38 and PHRCN 2012 12-006-0347), the Agence Nationale de la Recherche (ANR LONGVIE 2007), Fondation Plan Alzheimer (Alzheimer Plan 2008-2012), Fondation LECMA-Vaincre Alzheimer (grant no. 13732), Association France Alzheimer et maladies apparentées, the Région Basse-Normandie, the Agence régionale de santé Auvergne-Rhône-Alpes, and the European Union's Horizon 2020 Research and Innovation Program (grant 667696). Funding sources were not involved in the study design, data acquisition, analysis, and manuscript writing.

\section{Availability of data and materials}

Data related to the current study are derived from the IMAP study. The datasets used and/or analyzed during the current study are available from the corresponding author on reasonable request.

\section{Ethics approval and consent to participate}

The IMAP study was approved by a regional ethics committee (Comité de Protection des Personnes Nord-Ouest III) and registered at http://clinicaltrials. gov (no. NCT01638949). All participants gave their written informed consent to the study prior to enrollment.

\section{Consent for publication}

Not applicable

\section{Competing interests}

Antoine Garnier-Crussard reports no competing interests.

Salma Bougacha reports no competing interests.

Miranka Wirth reports no competing interests.

Claire André reports no competing interests.

Marion Delarue reports no competing interests.

Brigitte Landeau reports no competing interests.

Florence Mézenge reports no competing interests.

Elizabeth Kuhn reports no competing interests.

Julie Gonneaud reports no competing interests.

Anne Chocat reports no competing interests.

Anne Quillard reports no competing interests.

Eglantine Ferrand Devouge reports no competing interests.

Vincent de la Sayette reports no competing interests.

Denis Vivien reports no competing interests.

Pierre Krolak-Salmon reports no competing interests.

Gaël Chételat reports no competing interests.

\section{Author details}

'Normandie Univ, UNICAEN, INSERM, U1237, PhIND "Physiopathology and Imaging of Neurological Disorders", Institut Blood and Brain @ Caen-Normandie, Cyceron, 14000 Caen, France. ${ }^{2}$ Clinical and Research Memory Center of Lyon, Lyon Institute For Elderly, Charpennes Hospital, Hospices Civils de Lyon, Lyon, France. ${ }^{3}$ Claude Bernard University Lyon 1, Lyon, France. ${ }^{4}$ German Center for Neurodegenerative Diseases (DZNE), Dresden, Germany. ${ }^{5}$ Normandie Univ, UNICAEN, PSL Université, EPHE, INSERM, U1077, CHU de Caen, GIP Cyceron, NIMH, Caen, France. ${ }^{6}$ Department of General Practice, Normandie Univ, UNIROUEN, Rouen, France. ${ }^{7}$ Rouen University Hospital, Inserm CIC-CRB 1404, F-76 000 Rouen, France. ${ }^{8}$ Department of Neurology, CHU de Caen, Caen, France. ${ }^{9}$ Department of Clinical Research, CHU de Caen, Caen, France. ${ }^{10}$ Lyon Neuroscience Research Centre, INSERM 1028, CNRS 5292, Lyon, France.

Received: 11 May 2020 Accepted: 17 August 2020

Published online: 08 October 2020

\section{References}

1. Prins ND, Scheltens P. White matter hyperintensities, cognitive impairment and dementia: an update. Nat Rev Neurol. 2015;11:157-65.

2. Kloppenborg RP, Nederkoorn PJ, Geerlings MI, van den Berg E. Presence and progression of white matter hyperintensities and cognition: a metaanalysis. Neurology. 2014;82:2127-38.

3. Hopkins RO, Beck CJ, Burnett DL, Weaver LK, Victoroff J, Bigler ED. Prevalence of white matter hyperintensities in a young healthy population. J Neuroimaging. 2006;16:243-51.

4. Habes M, Sotiras A, Erus G, Toledo JB, Janowitz D, Wolk DA, et al. White matter lesions: spatial heterogeneity, links to risk factors, cognition, genetics, and atrophy. Neurology. 2018;91:e964-75.

5. Wen W, Sachdev PS, Li JJ, Chen X, Anstey KJ. White matter hyperintensities in the forties: their prevalence and topography in an epidemiological sample aged 44-48. Hum Brain Mapp. 2009;30:1155-67.

6. King KS, Peshock RM, Rossetti HC, McColl RW, Ayers CR, Hulsey KM, et al. Effect of normal aging versus hypertension, abnormal body mass index, and diabetes mellitus on white matter hyperintensity volume. Stroke. 2014;45: 255-7.

7. Moura AR, Lee S, Habeck C, Razlighi Q, Stern Y. The relationship between white matter hyperintensities and cognitive reference abilities across the life span. Neurobiol Aging. 2019;83:31-41.

8. Vannorsdall TD, Waldstein SR, Kraut M, Pearlson GD, Schretlen DJ. White matter abnormalities and cognition in a community sample. Arch Clin Neuropsychol. 2009;24:209-17.

9. Bunce D, Anstey KJ, Cherbuin N, Burns R, Christensen H, Wen W, et al. Cognitive deficits are associated with frontal and temporal lobe white matter lesions in middle-aged adults living in the community. PLoS One. 2010;5:e13567.

10. Soriano-Raya JJ, Miralbell J, López-Cancio E, Bargalló N, Arenillas JF, Barrios $\mathrm{M}$, et al. Deep versus periventricular white matter lesions and cognitive function in a community sample of middle-aged participants. J Int Neuropsychol Soc. 2012;18:874-85.

11. Brugulat-Serrat A, Salvadó G, Sudre CH, Grau-Rivera O, Suárez-Calvet M, Falcon C, et al. Patterns of white matter hyperintensities associated with cognition in middleaged cognitively healthy individuals. Brain Imaging Behav. 2019. https:/doi.org/10, 1007/s11682-019-00151-2.

12. Smith EE, O'Donnell M, Dagenais G, Lear SA, Wielgosz A, Sharma M, et al. Early cerebral small vessel disease and brain volume, cognition, and gait. Ann Neurol. 2015;77:251-61.

13. d'Arbeloff T, Elliott ML, Knodt AR, Melzer TR, Keenan R, Ireland D, et al. White matter hyperintensities are common in midlife and already associated with cognitive decline. Brain Commun. 2019;1:7.

14. Debette S, Seshadri S, Beiser A, Au R, Himali JJ, Palumbo C, et al. Midlife vascular risk factor exposure accelerates structural brain aging and cognitive decline. Neurology. 2011;77:461-8.

15. Livingston G, Sommerlad A, Orgeta V, Costafreda SG, Huntley J, Ames D, et al. Dementia prevention, intervention, and care. Lancet. 2017;390:2673-734.

16. Jack CR, Wiste HJ, Weigand SD, Knopman DS, Vemuri P, Mielke MM, et al. Age, sex, and APOE $\varepsilon 4$ effects on memory, brain structure, and $\beta$-amyloid across the adult life span. JAMA Neurol. 2015:72:511-9. 
17. Gonneaud J, Arenaza-Urquijo EM, Mézenge F, Landeau B, Gaubert M, Bejanin A, et al. Increased florbetapir binding in the temporal neocortex from age 20 to 60 years. Neurology. 2017;89:2438-46.

18. Marnane M, Al-Jawadi OO, Mortazavi S, Pogorzelec KJ, Wang BW, Feldman $\mathrm{HH}$, et al. Periventricular hyperintensities are associated with elevated cerebral amyloid. Neurology. 2016;86:535-43.

19. Roseborough A, Ramirez J, Black SE, Edwards JD. Associations between amyloid $\beta$ and white matter hyperintensities: a systematic review. Alzheimers Dement. 2017;13:1154-67.

20. Graff-Radford J, Arenaza-Urquijo EM, Knopman DS, Schwarz CG, Brown RD, Rabinstein AA, et al. White matter hyperintensities: relationship to amyloid and tau burden. Brain. 2019;142:2483-91.

21. Sweeney MD, Montagne A, Sagare AP, Nation DA, Schneider LS, Chui HC, et al. Vascular dysfunction-the disregarded partner of Alzheimer's disease. Alzheimers Dement. 2019;15:158-67.

22. Haight TJ, Landau SM, Carmichael O, Schwarz C, DeCarli C, Jagust WJ, et al. Dissociable effects of Alzheimer disease and white matter hyperintensities on brain metabolism. JAMA Neurol. 2013;70:1039-45.

23. Kalaria RN, Ihara M. Dementia: vascular and neurodegenerative pathways-will they meet? Nat Rev Neurol. 2013;9:487-8.

24. Gordon BA, Najmi S, Hsu P, Roe CM, Morris JC, Benzinger TLS. The effects of white matter hyperintensities and amyloid deposition on Alzheimer dementia. Neuroimage Clin. 2015;8:246-52.

25. Dupont PS, Bocti C, Joannette M, Lavallée MM, Nikelski J, Vallet GT, et al. Amyloid burden and white matter hyperintensities mediate age-related cognitive differences. Neurobiol Aging. 2020;86:16-26.

26. Rabin JS, Schultz AP, Hedden T, Viswanathan A, Marshall GA, Kilpatrick E, et al. Interactive associations of vascular risk and $\beta$-amyloid burden with cognitive decline in clinically normal elderly individuals: findings from the Harvard aging brain study. JAMA Neurol. 2018;75:1124.

27. La Joie R, Perrotin A, Barré L, Hommet C, Mézenge F, Ibazizene M, et al. Region-specific hierarchy between atrophy, hypometabolism, and $\beta$-amyloid $(A \beta)$ load in Alzheimer's disease dementia. J Neurosci. 2012;32:16265-73.

28. Besson FL, La Joie R, Doeuvre L, Gaubert M, Mézenge F, Egret S, et al. Cognitive and brain profiles associated with current neuroimaging biomarkers of preclinical Alzheimer's disease. J Neurosci. 2015;35:10402-11.

29. Grober E, Buschke H, Crystal H, Bang S, Dresner R. Screening for dementia by memory testing. Neurology. 1988;38:900.

30. Mattis S. Mental status examination for organic mental syndrome in the elderly patients. Bellack, L. and Karusu, T.B., Eds., Geriatric Psychiatry, Grune\&Stratton. New York; 1976.

31. Eustache F, Laisney M, Lalevée C, Pèlerin A, Egret S, Chetelat G, et al. Une nouvelle épreuve de mémoire épisodique : l'épreuve ESR-forme réduite (ESR-r), adaptée du paradigme ESR (encodage, stockage, récupération). Rev Neuropsychol. 2015;7:217-25.

32. Godefroy O, GREFEX. Fonctions exécutives et pathologies neurologiques et psychiatriques. Évaluation en pratique clinique Solal Marseille. 2008. https:// www.unitheque.com/fonctions-executives-pathologies-neurologiquespsychiatriques/neuropsychologie/solal/Livre/19132? gclid= EAlalQobChMlvZOnIMG96wIWLLVCh0eAAgHEAQYASABEgKI1PD_BwE.

33. Petermann F, Wechsler DJ. Wechsler Adult Intelligence Scale - fourth edition; 2012

34. Schmidt P. Bayesian inference for structured additive regression models for large-scale problems with applications to medical imaging [Text.PhDThesis]. Ludwig-Maximilians-Universität München; 2017. Available from: https://edoc ub.uni-muenchen.de/20373/. [cited 2018 Dec 27].

35. Wirth AM, Johannesen S, Khomenko A, Baldaranov D, Bruun T-H, Wendl C, et al. Value of fluid-attenuated inversion recovery MRI data analyzed by the lesion segmentation toolbox in amyotrophic lateral sclerosis. J Magn Reson Imaging. 2019;50:552-9.

36. Wardlaw JM, Valdés Hernández MC, Muñoz-Maniega S. What are white matter hyperintensities made of? Relevance to vascular cognitive impairment. J Am Heart Assoc. 2015:4:e001140.

37. Hammers A, Allom R, Koepp MJ, Free SL, Myers R, Lemieux L, et al. Threedimensional maximum probability atlas of the human brain, with particular reference to the temporal lobe. Hum Brain Mapp. 2003;19:224-47.

38. Wakana S, Caprihan A, Panzenboeck MM, Fallon JH, Perry M, Gollub RL, et al. Reproducibility of quantitative tractography methods applied to cerebral white matter. Neuroimage. 2007;36:630-44.
39. Hua K, Zhang J, Wakana S, Jiang H, Li X, Reich DS, et al. Tract probability maps in stereotaxic spaces: analyses of white matter anatomy and tractspecific quantification. Neuroimage. 2008;39:336-47.

40. André $C$, Tomadesso $C$, de Flores $R$, Branger $P$, Rehel $S$, Mézenge $F$, et al. Brain and cognitive correlates of sleep fragmentation in elderly subjects with and without cognitive deficits. Alzheimers Dement. 2019; 11:142-50.

41. Jack CR, Wiste HJ, Weigand SD, Therneau TM, Lowe VJ, Knopman DS, et al. Defining imaging biomarker cut points for brain aging and Alzheimer's disease. Alzheimers Dement. 2017;13:205-16.

42. Cox SR, Lyall DM, Ritchie SJ, Bastin ME, Harris MA, Buchanan CR, et al. Associations between vascular risk factors and brain MRI indices in UK Biobank. Eur Heart J. 2019;40:2290-300.

43. de Leeuw F-E, de Groot JC, Achten E, Oudkerk M, Ramos L, Heijboer R, et al. Prevalence of cerebral white matter lesions in elderly people: a population based magnetic resonance imaging study. The Rotterdam Scan Study. J Neurol Neurosurg Psychiatry. 2001;70:9-14.

44. Pantoni L. Cerebral small vessel disease: from pathogenesis and clinical characteristics to therapeutic challenges. Lancet Neurol. 2010;9:689-701.

45. Launer LJ. Epidemiology of white matter lesions. Top Magn Reson Imaging. 2004;15:365-7.

46. Bolandzadeh N, Davis JC, Tam R, Handy TC, Liu-Ambrose T. The association between cognitive function and white matter lesion location in older adults: a systematic review. BMC Neurol. 2012;12:126.

47. Jiang J, Paradise M, Liu T, Armstrong NJ, Zhu W, Kochan NA, et al. The association of regional white matter lesions with cognition in a community-based cohort of older individuals. Neuroimage Clin. 2018;19: 14-21.

48. Giorgio A, Di Donato I, De Leucio A, Zhang J, Salvadori E, Poggesi A, et al. Relevance of brain lesion location for cognition in vascular mild cognitive impairment. Neuroimage Clin. 2019;22:101789.

49. Tullberg M, Fletcher E, DeCarli C, Mungas D, Reed BR, Harvey DJ, et al. White matter lesions impair frontal lobe function regardless of their location. Neurology. 2004;63:246-53.

50. Hedden T, Mormino EC, Amariglio RE, Younger AP, Schultz AP, Becker JA, et al. Cognitive profile of amyloid burden and white matter hyperintensities in cognitively normal older adults. J Neurosci. 2012;32:16233-42.

51. Vemuri P, Lesnick TG, Przybelski SA, Knopman DS, Preboske GM, Kantarci K, et al. Vascular and amyloid pathologies are independent predictors of cognitive decline in normal elderly. Brain. 2015;138:761-71.

52. Marchant NL, Reed BR, DeCarli CS, Madison CM, Weiner MW, Chui HC, et al. Cerebrovascular disease, $\beta$-amyloid, and cognition in aging. Neurobiol Aging. 2012;33:1006.e25-36.

53. Lee MJ, Seo SW, Na DL, Kim C, Park JH, Kim GH, et al. Synergistic effects of ischemia and $\beta$-amyloid burden on cognitive decline in patients with subcortical vascular mild cognitive impairment. JAMA Psychiatry. 2014;71: 412-22

54. Walsh P, Sudre CH, Fiford CM, Ryan NS, Lashley T, Frost C, et al. CSF amyloid is a consistent predictor of white matter hyperintensities across the disease course from aging to Alzheimer's disease. Neurobiol Aging. 2020;91:5-14.

\section{Publisher's Note}

Springer Nature remains neutral with regard to jurisdictional claims in published maps and institutional affiliations.

Ready to submit your research? Choose BMC and benefit from:

- fast, convenient online submission

- thorough peer review by experienced researchers in your field

- rapid publication on acceptance

- support for research data, including large and complex data types

- gold Open Access which fosters wider collaboration and increased citations

- maximum visibility for your research: over $100 \mathrm{M}$ website views per year

At $\mathrm{BMC}$, research is always in progress.

Learn more biomedcentral.com/submissions 